\title{
Discussion on the Quality of Green Tourism Services from the Viewpoint of Tourism Laws
}

\author{
Cheng-Kuang Wang ${ }^{1,2}$, Bi-Ru Lee ${ }^{1}$, Guilan Huang ${ }^{2}$ \\ ${ }^{1}$ Law School, Nankai University, Tianjin 300071, China \\ ${ }^{2}$ Zhongshan Institute, University of Electronic Science and Technology of China, Guangdong 528402, \\ China
}

richardkuang@yahoo.com.tw, maggen_lee@hotmail.com,1909369750@qq.com

\begin{abstract}
Green tourism refers to all aspects in the whole process of tourism of travel participants including tourists, travel agencies and tour guides, hotels, and scenic spot managers. They must respect the nature and protect the environment. Tourists in the green tourism process no longer only passively have appreciation and entertainment. They participate in more practical actions to protect the environment, thereby enhancing the environmental protection awareness of the tourists themselves. Currently green low-carbon tourism products are still in the initial development stage. Bother government agencies and many private enterprises dare not invest too many resources in their green tourism products, so how to clearly grasp and strengthen the quality factors to improve consumer satisfaction in the event of resource shortage should be the key for tourism products to successfully opening the market. This study uses the importance-performance analysis method, hoping to find the factors that really impact green tourism customer satisfaction, to provide design approaches for future practitioners to develop green low-carbon tourism products, and to concentrate resources to improve the key factors of quality.
\end{abstract}

Keywords: green tourism, quality factors, Importance-Performance Analysis Model, tourism laws, service quality

\section{Introduction}

For consumers, green low-carbon tourism not only represents energy saving and environmental protection, but also may produce additional costs, such as additional costs generated by renting a bike or electric car, and labor required for and less convenience of walking or cycling than motor vehicles, so that many consumers are deterred. Currently low-carbon tourism products in Taiwan are mainly planned by the government, and provided for the public to participate at a low price or even free-of-charge. Although with a good response, whether the purpose of the travel, for the public, is to respond to environmentally friendly carbon reduction, or only to draw their interest by low prices in the economic downturn is doubtful.

Most of previous tourism-related researches containing the concept of environmental protection focus on such topics as ecotourism and rural tourism. Researches on green tourism in Taiwan are mostly only about exploring the greening mode and benefits of a certain link in the tourism supply chain, such as green guest houses and green consumption behaviors. Researches on green tourism or low-carbon tourism products are relatively rare. However, there are many successful green tourism stories and related researches overseas, showing that green tourism has its promotional value[1-3].

With the advancement of national income, traveling has become a part of the life of a lot of people, and because the travel of a large number of travelers causes too much traffic and additional accommodation, too much energy is consumed. According to the report of the World Economic Forum, the carbon emission of the tourism industry (including the transportation industry related to tourism) accounts for $5 \%$ of the world's total, of which the transportation industry accounts for $2 \%$ and the pure tourism industry accounts for 3\%[4]. According to Tsai et al.1, it is undeniable that tourism practitioners and travelers themselves also contribute to today's global greenhouse effect, but the GDP of tourism-related industries in the global GDP has reached $9.2 \%$ and is forecast to grow to $9.5 \%$ by 2020 , indicating that modern traveling demand is inevitable. As a member of the earth, we all have the responsibility and obligation to promote and practice low-carbon green tourism. 
Currently green low-carbon tourism products are still in the initial development stage. Bother government agencies and many private enterprises dare not invest too many resources in their green tourism products, so how to clearly grasp and strengthen the quality factors to improve consumer satisfaction in the event of resource shortage should be the key for tourism products to successfully opening the market.

This paper analyzes the content of green tourism literature and hopes to find out the quality factors in green tourism that affect customer satisfaction in order to provide design approaches for future practitioners to develop green low-carbon tourism products and to analyze the competition strategies of the practitioners.

\section{Literature Review: Green Tourism}

Green tourism refers to all aspects in the whole process of tourism of travel participants including tourists, travel agencies and tour guides, hotels, and scenic spot managers. They must respect the nature and protect the environment[5-6]. Tourists in the green tourism process no longer only passively have appreciation and entertainment. They participate in more practical actions to protect the environment, thereby enhancing the environmental protection awareness of the tourists themselves. Thea[7] further pointed out that green tourism is the use and utilization of resources and the environment through the principles of resource reduction, repeated use and recycling by the tourism system during operation to achieve the high efficiency of resource utilization and the economic development mode that minimizes environmental damage. Green and environmental protection are closely integrated, so that consumers can understand the nature and enjoy the nature at the same time.

Simpson et al.[4] argued that green tourism is actually a low-carbon lifestyle for individuals, and the following three points are needed to translate it into an action of tourists:

To change the existing tourism mode, promote public transport and hybrid vehicles, electric cars, bicycles and other low-carbon or carbon-free transportation, and at the same time enrich tourism life and increase tourism projects.

To avoid extravagance and waste, strengthen the functions of cleanness, convenience and comfort, and enhance the brand nature of culture.

To strengthen the intelligent development of tourism, improve operational efficiency, and at the time introduce energy-saving carbon reduction technologies, reduce carbon emissions, and ultimately form the circular economy mode of the entire supply chain.

Green tourism defined by the Green Tourism Association of Taiwan (GTAT) is "the travel experience of travelers where they enjoy ecological humanism in the tourism form with the smallest impact on the environment pursuant to the spirit of energy saving and carbon reduction". It further put forward the specific principles of green tourism as follows[7-9]:

Food: organic and seasonal. Dining should be based on environmentally organic and local seasonal ingredients in order to reduce land pollution and energy consumption of transport.

Clothing: light and comfortable. Wearing light and environmentally friendly clothing which is comfortable and breathable cannot only achieve baggage reduction, but also reduce transport, cleaning and energy consumption.

Living: energy-saving and local. The concept of environmental protection and energy saving should be entertained, and priority should be given to green hotels or restaurants using local building materials and local staff.

Traveling: public and low-carbon. During traveling, public transport, cycling, walking or low-carbon energy-saving means of transport should be given priority.

Cultivation: respect for nature. Natural tourist destinations should not be violated and coexistence with tourist destinations should be achieved pursuant to the spirit of environmental protection 3R (Reduce, Reuse, Recycle).

Joy: care experience. Tourists walk into mountains, seas and urban and rural areas, communities and clusters, farms and forests, as well as fields and wetlands to care about environmental ecology as well as 
humanistic landscape and local customs.

Purchase: local specialties. Tourists purchase local produce and craft souvenirs at tourist destinations to increase the income of local business owners and reduce the energy consumption of transportation.

From the seven principles it can be seen that the current green tourism in Taiwan emphasizes that the environment should not be disturbed, and that tourists should go on in-depth tours where they can fully learn about the local nature and humanity. What is more noteworthy is that, unlike other countries, it pays more attention to the reduction of carbon emissions during the tour process.

This study presents 10 indicators of green tourism quality factors to measure the performance of green tourism quality. Please refer to Table 1 for these 10 indicators.

\section{Research Method}

\subsection{Importance-Performance Analysis}

The relevant basic architecture of importance-performance analysis (IPA) was first proposed and applied by Martilla and James[10]. By IPA the average importance and performance scores of attributes are drawn into a two-dimensional graph, where the vertical axis represents the degree of importance, and the horizontal axis represents the degree of performance, as shown in Figure 1[11-16].

There are four quadrants in the IPA method, each of which has its own definition [17-23]:

Keep up the good work: It means that customers attach great importance to the attributes of this area, and are satisfied with the performance of the enterprise, so the attributes falling in this quadrant belong to "Keep up the good work".

Concentrate here: It means that customers attach great importance to the attributes of this area, but are not satisfied with the performance of the company, so the attributes falling in this quadrant belong to "Concentrate here".

Low priority: It means that customers attach little importance to the attributes of this area, and are not satisfied with the performance of the company, so the attributes falling in this quadrant belong to "Low priority".

Possible overkill: It means that customers attach little importance to the attributes of this area, but are satisfied with the performance of the enterprise, so the attributes falling in this quadrant belong to "Possible overkill".

By the division of different areas, managers can make the most efficient use of limited resources and provide improvement priorities to increase satisfaction. The IPA method is a way to easily analyze the good and bad as well as improvement of attributes. It is heavily applied by scholars in other areas to serve as a tool to analyze attribute improvement priorities and to meet customer needs[24-28].

Importance

\begin{tabular}{c|c} 
Concentrate here & Keep up the good work \\
\hline Low priority & Performance \\
\hline
\end{tabular}

Figure 1 Importance and Performance Analysis Chart 


\subsection{Research Cases}

T Company is the third largest domestic tourism company in Taiwan. This study takes T Company as a research subject to evaluate the performance of green tourism quality of the company, which serves as a basis for improvement of the company.

The questionnaire uses the Likert 7-point scale, with a total of 10 questions, starting on April 5, 2016 and ending on April 25, 2016. 350 customers of T Company were surveyed. The total number of formal questionnaires distributed was 350, of which the effective questionnaires recovered were 296 . The effective recovery rate was $84.57 \%$.

\section{Research Results and Discussion}

This study uses the mean value of importance (5.85) and the mean value of performance (5.78) concluded from the questionnaire as the standard coordinates to determine the good or bad performance of each quality factor. See Table 1 for details.

According to the results of IPA, the four attributes that (4) "green tourism" is used as the advertising slogan, (6) the local ecological environment will not be disturbed in the tourism process, (7) tour guides in the tourism process will not destroy the environment and (9) tour guides and local residents are committed to protecting the local environment, which belong to "Keep up the good work", are T Company's strength and need to be continued. The maintenance of quality performance can help the company win the green tourism reputation.

T Company is competitively disadvantaged in the three attributes that (2) local food specialties are mostly made from local ingredients, (5) the green concept is integrated into the local sightseeing seasons or festival activities and (10) tourists learn about the local culture by direct experience. The attributes belong to "Concentrate here". T Company must concentrate resources to enhance the performance of these three attributes. Only in this way can the disadvantage be reversed and competitiveness be improved.

In addition, the two attributes that (1) public transport or shuttle buses is used to travel to tourist destinations and (8) tour guides encourage tourists to participate in the life of local residents and to understand the local culture, belong to "Low priority". The performance of T Company is not good, and the importance is low, so they can be put in the final position. When the company has excess resources, improvement can be made. Finally, the importance of the attribute that (3) tour guides give detailed and professional introductions to the local natural ecology, history and humanity is low, but the performance is high. It belongs to "Possible overkill." T Company's performance is good, but it cannot bring more performance for the company. It should be considered that corporate resources are transferred to other attributes. See Table 1 for details.

Table 1 Analysis of the Importance and Performance of 10 Green Tourism Quality Attributes

\begin{tabular}{|l|l|c|c|l|}
\hline $\begin{array}{l}\text { Questi } \\
\text { on }\end{array}$ & Quality Factor & $\begin{array}{l}\text { Importa } \\
\text { nce }\end{array}$ & $\begin{array}{l}\text { Performa } \\
\text { nce }\end{array}$ & Competition Strategy \\
\hline 1 & $\begin{array}{l}\text { Public transport or shuttle buses are used to } \\
\text { travel to tourist destinations. }\end{array}$ & 5.4 & 5.6 & Low priority \\
\hline 2 & $\begin{array}{l}\text { Local food specialties are mostly made from } \\
\text { local ingredients. }\end{array}$ & 5.9 & 5.4 & Concentrate here \\
\hline 3 & $\begin{array}{l}\text { Tour guides give detailed and professional } \\
\text { introductions to the local natural ecology, } \\
\text { history and humanity. }\end{array}$ & 5.4 & 5.9 & Possible overkill \\
\hline 5 & $\begin{array}{l}\text { "Green tourism" is used as the advertising } \\
\text { slogan. }\end{array}$ & 6.2 & 6.3 & $\begin{array}{l}\text { Keep up the good } \\
\text { work }\end{array}$ \\
\hline 5 & $\begin{array}{l}\text { The green concept is integrated into the local } \\
\text { sightseeing seasons or festival activities. }\end{array}$ & 6.1 & 5.6 & Concentrate here \\
\hline
\end{tabular}




\begin{tabular}{|l|l|c|c|l|}
\hline \multicolumn{2}{|l|}{ Table 1, cont. } & 6.0 & $\begin{array}{l}\text { Keep up the good } \\
\text { work }\end{array}$ \\
\hline 6 & $\begin{array}{l}\text { The local ecological environment will not be } \\
\text { disturbed in the tourism process. }\end{array}$ & 6.0 & $\begin{array}{l}\text { Keep up the good } \\
\text { work }\end{array}$ \\
\hline 7 & $\begin{array}{l}\text { Tour guides in the tourism process will not } \\
\text { destroy the environment. }\end{array}$ & 6.0 & 5.6 & Low priority \\
\hline 8 & $\begin{array}{l}\text { Tour guides encourage tourists to participate } \\
\text { in the life of local residents and to } \\
\text { understand the local culture. }\end{array}$ & 5.5 & 5.9 & $\begin{array}{l}\text { Keep up the good } \\
\text { work }\end{array}$ \\
\hline $\begin{array}{l}\text { Tour guides and local residents are } \\
\text { committed to protecting the local } \\
\text { environment. }\end{array}$ & $\begin{array}{l}\text { Tourists learn about the local culture by } \\
\text { direct experience. }\end{array}$ & 6.1 & 5.6 & Concentrate here \\
\hline $\begin{array}{l}\text { Avera } \\
\text { ge }\end{array}$ & & 5.83 & 5.75 & \\
\hline
\end{tabular}

\section{Conclusion}

Currently green low-carbon tourism products are still in the initial development stage. Bother government agencies and many private enterprises dare not invest too many resources in their green tourism products, so how to clearly grasp and strengthen the quality factors to improve consumer satisfaction in the event of resource shortage should be the key for tourism products to successfully opening the market.

This study presents 10 indicators of green tourism quality factors to measure the performance of green tourism quality, which serves as a basis for improvement of the subject company.

According to the results of IPA, T Company is competitively advantaged in the four attributes of (4) (6) (7) (9), which are T Company's strength and need to be continued. The quality performance should be maintained. T Company is competitively disadvantaged in the three attributes of (2) (5) (10). T Company must concentrate resources to enhance the performance of these three attributes. Only in this way can the disadvantage be reversed and competitiveness be improved.

\section{References:}

[1] Tsai, S.B., Wei, Y.M., Chen, K.Y., Xu, T., et al. 2016. Evaluating Green Suppliers from Green Environmental Perspective. Environment and Planning B-Planning \& Design, 2016, 43(5), 941-959.

[2] Tsai, S.B. 2016. Using Grey Models for Forecasting China's Growth Trends in Renewable Energy Consumption. Clean Technologies and Environmental Policy, 2016, 18, 563-571.

[3] Zhang, X., Deng Y., Chan, F. T., Xu, P., et al. 2013. IFSJSP: A novel methodology for the Job-Shop Scheduling Problem based on intuitionistic fuzzy sets. International Journal of Production Research, 2013, 51(17), 5100-5119.

[4] Simpson, M.C., Gössling, S., Scott, D., Hall, C.M. \& Gladin, E., 2008. Climate Change Adaptation and Mitigation in the Tourism Sector: Frameworks, Tools and Practices, UNEP, University of Oxford, UNWTO, WMO: Paris, France.

[5] Smith, L.J. 1994. The tourism product. Annals of Tourism Research, 21(3), 582-593.

[6] Tan, K.C. \& Pawitra, T.A. 2001. Integrating SERVQUAL and Kano's Model into QFD for Service Excellence Development, Managing Service Quality, 11(6), 418-430.

[8] Thea, Chiesa. 2009. Towards a Low Carbon Travel \& Tourism Sector, Head Aviation, Travel \& Tourism, World Economic Forum. 
[9] Guo, J.J. and Tsai, S.B. 2015. Discussing and Evaluating Green Supply Chain Suppliers: A Case Study of the Printed Circuit Board Industry in China. South African Journal of Industrial Engineering, 2015, 26(2), 56-67.

[10] Tsai, S.B., Huang, C.Y., Wang, C.K., Chen, Q., et al. 2016. Using a Mixed Model to Evaluate Job Satisfaction in High-Tech Industries. Plos One, 2016, 11(5): e0154071. doi:10.1371/journal.pone.0154071

[11] Martilla, J. A. \& James, J. C. 1977. Importance-Performance Analysis. Journal of Marketing, 41 (1), 77-79.

[12] Lee, Y.C., Chu, W.H., Chen, Q., Tsai, S.B., et al. 2016. Integrating DEMATEL Model and Failure Mode and Effects Analysis to Determine the Priority in Solving Production Problems. Advances in Mechanical Engineering, 2016, 8(4), 1-12.

[13] Tsai, S.B., Xue, Y., Zhang, J., Chen, Q., et al. 2016. Models for Forecasting Growth Trends in Renewable Energy. Renewable \& Sustainable Energy Reviews, 2016, DOI: 10.1016/j.rser.2016.06.001.

[14] Qu, Q., Chen, K.Y., Wei, Y.M., et al. 2015. Using Hybrid Model to Evaluate Performance of Innovation and Technology Professionals in Marine Logistics Industry Mathematical Problems in Engineering, 2015, Article ID 361275, 8 pages, http://dx.doi.org/10.1155/2015/361275.

[15] Zhou, J. Wang, Q., Tsai, S.B., et al. 2016. How to Evaluate the Job Satisfaction of Development Personnel. IEEE Transactions On Systems Man Cybernetics-Systems, 2016, 10.1109/TSMC.2016.2519860.

[16] Tsai, S.B., Li, G., Wu, C.H., Zheng, Y., et al. 2016. An empirical research on evaluating banks' credit assessment of corporate customers. SpringerPlus, 2016, 5:2088. DOI 10.1186/s40064-016-3774-0.

[17] Su, J. M., Lee, S. C., Tsai, S. B. \& Lu, T. L. 2016. A comprehensive survey of the relationship between self-efficacy and performance for the governmental auditors. SpringerPlus, 2016, 5:508. DOI 10.1186/s40064-016-2104-x.

[18] Tsai, S.B., Lee, Y.C. \& Guo, J.J. 2014. Using modified grey forecasting models to forecast the growth trends of green materials. Proceedings of the Institution of Mechanical Engineers, Part B: Journal of Engineering Manufacture, 2014, 228(6): 931-940.

[19] Tsai, S.B., Chen, K.Y., Zhao, H., Wei, Y.M., et al. 2016. Using a Mixed Model to Explore Evaluation Criteria for Bank Supervision: A Banking Supervision Law Perspective. PLoS ONE, 2016, 11(12): e0167710. doi:10.1371/journal.pone.0167710

[20] Chen, H.M., Wu, C.H., Tsai, S.B., Yu, J., et al. 2016. Exploring key factors in online shopping with a hybrid model. SpringerPlus, 2016, 5:2046. DOI 10.1186/s40064-016-3746-4.

[21] Deng, X.Y., Hu, Y., Deng Y. \& Mahadevan, S. 2014. Environmental impact assessment impact assessment based on numbers. Expert Systems with Applications, 2014, 41 (2), 635-643.

[22] Wang, J., Yang, J., Chen Q. \& Tsai, S.B. 2016. Collaborative Production Structure of Knowledge-sharing Behavior in Internet Communities. Mobile Information Systems, Article ID 8269474, 9 pages, http://dx.doi.org/10.1155/2016/8269474.

[23] Wang, J., Yang, J., Chen Q. \& Tsai, S.B. 2016. Creating the Sustainable Conditions for Knowledge Information Sharing in Virtual Community. SpringerPlus, 5:1019, DOI 10.1186/s40064-016-2702-7.

[24] Lee, Y.C., Wang, Y.C., Chien, C.H., Wu, C.H., et al. 2016. Applying Revised Gap Analysis Model in Measuring Hotel Service Quality, SpringerPlus, 5:1191, DOI 10.1186/s40064-016-2823-z. 
[25] Lee, Y.C., Wang, Y.C., Lu, S.C., Hsieh, Y.F., et al. 2016. An Empirical Research on Customer Satisfaction Study: A Consideration of Different Levels of Performance. SpringerPlus, 5:1577, DOI 10.1186/s40064-016-3208-z.

[26] Chin, T., Tsai, S.B., Fang, K., Zhu, W., et al. 2016. EO-Performance relationships in Reverse Internationalization by Chinese Global Startup OEMs: Social Networks and Strategic Flexibility. PLoS ONE, 11(9): e0162175, doi:10.1371/journal.pone.0162175.

[27] Lee, S.C., Su, J.M., Tsai, S.B., Lu, T.L., et al. 2016. A comprehensive survey of government auditors' self-efficacy and professional Development for improving audit quality. SpringerPlus, 5:1263, DOI 10.1186/s40064-016-2903-0.

[28] Chen, H.M., Wu, C.H., Tsai, S.B., Yu, J., et al. 2016. Exploring key factors in online shopping with a hybrid model. SpringerPlus, 5:2046, DOI 10.1186/s40064-016-3746-4.

[29] Ge, B., Jiang, D., Gao, Y., \& Tsai, S.B. 2016. The Influence of Legitimacy on a Proactive Green Orientation and Green Performance: A Study Based on Transitional Economy Scenarios in China. Sustainability, 8, 1344, 1-20. doi:10.3390/su8121344. 